\title{
Pengaruh Struktur Aktiva, Perputaran Total Asset, Perputaran Aktiva Tetap, dan Laverage Terhadap Profitabilitas (ROA)
}

\author{
Friska Darnawaty Sitorus ${ }^{1 *}$, Rafiq Christiadi ${ }^{2}$, Bunga Roito Br Silalahi ${ }^{3}$, Shelly ${ }^{4}$, \\ Debora Laia ${ }^{5}$ \\ ${ }_{1,2,3,4,5)}$ Universitas Prima Indonesia \\ friskadarnawaty1704@ gmail,com $^{1 *}, \underline{\text { rafiqchristiadi14@ gmail.com }}{ }^{2}, \underline{\text { bunga.roito19@ @mail.com }}{ }^{3}$, \\ shellyhuang19@ gmail.com ${ }^{4}$, deboralaia30@gmail.com ${ }^{5}$
}

*Corresponding Author

Diajukan : 25 Nopember 2021

Disetujui $\quad: 8$ Desember 2021

Dipublikasi : : 1 Januari 2022

\section{ABSTRACT}

This study aims to see the effect of asset structure, total asset turnover (TATO), fixed asset turnover, leverage (DER) on profitability (ROA) in building construction subsector companies registered on the IDX (Indonesian Stock Exchange). The sample used in this study is the building construction sub-sector companies registered on the BEI for the 2015-2019 period. The population in the study were 20 companies in the building construction sub-sector. The purposive sampling technique used in this study has a total sample of eighteen companies in the building construction sub-sector with a sample of 90 data. The data analysis technique used is multiple linear regression analysis with SPSS 20 software. The results of the study state that the asset structure has a significant positive effect on profitability (ROA). Total asset turnover (TATO) has a significant effect on profitability (ROA). Fixed asset turnover has a significant effect on profitability (ROA). Leverage (DER) has a negative and insignificant effect on profitability (ROA).

Keywords: Asset Structure; Fixed Asset Turnover; Leverage (DER); Profitability (ROA); Total Asset Turnover (TATO).

\section{Latar Belakang}

\section{PENDAHULUAN}

Perusahaan konstruksi yaitu bisnis yang berkaitan dengan hal merencanakan, melaksanakan, serta mengawasi sebuah aktivitas konstruksi sebagai pembentukan sebuah bangunan atau bentuk fisik lainnya. Ketika melaksanakan, menggunakan, ataupun memanfaatkan bangunan itu akan melibatkan adanya keselamatan dan kepentingan masyarakat pemakai bangunan.

Perkembangan kegiatan konstruksi di Indonesia yang pesat menimbulkan pengaruh pada persaingan antar perusahaan. Persaingan ini suatu upaya mempertahankan kelangsungan hidup dan mencapai laba perusahaan, sebab itu pelaku bisnis dituntut untuk meningkatkan kinerjanya. Suatu perusahaan mempunyai tujuan pokok utama yakni menghasilkan keuntungan, didapat dari penjualan produk maupun pelayanan. Kesanggupan perusahaan ketika memperoleh keuntungan dapat diukur melalui rasio profitabilitas.

Profitabilitas yaitu rasio yang dipergunakan sebagai pengukuran kesanggupan perusahaan ketika memperoleh hasil keuntungan dari kegiatan normal usahanya. Adanya 
tuntutan untuk manajemen agar menaikan return (imbal hasil) pemilik perusahaan, serta pula menambah kemakmuran pegawai. (Hery, 2015). Pada kajian ini profitabilitas diketahui mempergunakan ROA yakni kesanggupan perusahaan untuk mendapatkan hail keuntungan melalui aset yang dipunyai, sehingga pemanfaatan aset dalam kegiatan operasional perusahaan bisa dinilai tingkat efisiensinya.

Untuk menentukan besarnya bagian setiap komponen aktiva, baik aktiva tetap ataupun lancar yaitu menggunakan Struktur Aktiva. Sebagai pengukuran besarnya potensi perusahaan saat memperoleh hasil penjualan dari total aktiva yang dipunyai yaitu dari adanya penerapan rasio Perputaran Total Aset (TATO) dan Perputaran Aktiva Tetap. Sedangkan sebagai pengukuran berapa jauh aktiva perusahaan dibiayai menggunakan utang yaitu dari rasio Leverage (DER).

Tabel 1. Fenomena Penelitian

\begin{tabular}{|c|c|c|c|c|c|c|c|}
\hline $\begin{array}{c}\text { KODE } \\
\text { EMITME } \\
\text { N }\end{array}$ & Tahun & $\begin{array}{c}\text { Aktiva } \\
\text { Tetap }\end{array}$ & Total Aset & Penjualan & $\begin{array}{c}\text { Total } \\
\text { Hutang }\end{array}$ & $\begin{array}{c}\text { Total } \\
\text { Modal }\end{array}$ & $\begin{array}{c}\text { Laba } \\
\text { Bersih }\end{array}$ \\
\cline { 3 - 9 } & & \multicolumn{5}{|c|}{ (dalam Jutaan Rupiah) } \\
\hline \multirow{4}{*}{ WSKT } & 2015 & 1.390 .680 & 30.309 .111 & 14.152 .752 & 20.604 .904 & 9.704 .206 & 1.047 .590 \\
\cline { 2 - 9 } & 2016 & 1.710 .769 & 61.425 .181 & 23.788 .322 & 44.651 .963 & 16.773 .218 & 1.813 .068 \\
\cline { 2 - 9 } & 2017 & 4.742 .288 & 97.895 .760 & 45.212 .897 & 75.140 .936 & 22.754 .824 & 4.201 .572 \\
\cline { 2 - 9 } & 2018 & 7.091 .121 & 124.391 .581 & 48.788 .950 & 95.504 .462 & 28.887 .118 & 4.619 .567 \\
\cline { 2 - 8 } & 2019 & 8.663 .216 & 122.589 .259 & 31.387 .389 & 93.470 .790 & 29.118 .469 & 1.028 .898 \\
\hline \multirow{5}{*}{ JKON } & 2015 & 673.014 & 3.775 .957 & 4.655 .901 & 1.832 .112 & 1.943 .844 & 236.634 \\
\cline { 2 - 8 } & 2016 & 702.440 & 4.007 .387 & 4.650 .940 & 1.806 .636 & 2.200 .751 & 331.660 \\
\cline { 2 - 8 } & 2017 & 732.412 & 4.202 .515 & 4.495 .503 & 1.799 .503 & 2.403 .011 & 309.948 \\
\cline { 2 - 8 } & 2018 & 747.019 & 4.804 .256 & 5.157 .266 & 2.221 .760 & 2.582 .496 & 268.229 \\
\cline { 2 - 8 } & 2019 & 668.140 & 4.928 .108 & 5.470 .824 & 2.230 .341 & 2.697 .766 & 202.283 \\
\hline \multirow{5}{*}{ ADHI } & 2015 & 1.099 .426 & 16.761 .063 & 9.389 .570 & 11.598 .931 & 5.162 .131 & 465.025 \\
\cline { 2 - 8 } & 2016 & 1.459 .815 & 20.095 .435 & 11.063 .942 & 14.652 .655 & 5.442 .779 & 315.107 \\
\cline { 2 - 8 } & 2017 & 1.520 .930 & 28.332 .948 & 15.156 .178 & 22.463 .030 & 5.869 .917 & 517.059 \\
\cline { 2 - 8 } & 2018 & 1.573 .323 & 30.118 .614 & 15.655 .499 & 23.833 .342 & 6.285 .271 & 645.029 \\
\cline { 2 - 7 } & 2019 & 1.836 .864 & 36.515 .833 & 15.307 .860 & 29.681 .535 & 6.834 .297 & 665.048 \\
\hline
\end{tabular}

\section{STUDI LITERATUR}

\section{Teori Pengaruh Struktur Aktiva Pada Profitabilitas (ROA)}

Struktur aktiva yaitu perbandingan secara relatif ataupun absolut diantara aktiva tetap dan aktiva lancar. Arti absolut ini yaitu perimbangan yang berwujud nominal, sementara relatif yaitu perimbangan yang berwujud persentasi (Riyanto, 2013). Berdasarkan penelitian (Rahmi, 2019) bahwa struktur aktiva mempengaruhi secara signifikan profitabilitas. Bertambah besarnya aktiva tetap yang dimilik oleh perusahaan sehingga aktivitas pendanaan akan meninggi, hal tersebut dikarenakan total aktiva yang cenderung besar bisa sebagai penjaminan.

H1 : Struktur aktiva memberi pengaruh signifikan pada Profitabilitas (ROA).

\section{Teori Pengaruh Perputaran Total Aset Pada Profitabilitas (ROA)}

Menurut (Indriyani, 2017) semakin besar Perputaran Total Aset (Total Asset Turnover) akan membaik, sebab bertambah efektif keseluruhan aktiva yang dipergunakan sebagai penunjang aktivitas penjualan. Berdasarkan penelitian (Budiang, 2017) 
Perputaran total aset menunjukkan sebuah perusahaan yang semakin lancar dalam memperoleh hasil penjualan dari keseluruhan aset yang dipunyai perusahaan. Bertambah tingginya rasio ini memperlihatkan keberhasilan perusahaan menggunakan aktivanya saat memperoleh hasil penjualan. Dari bertambah besarnya penjualan serta pengeluaran beban yang kian mengecil sehingga bertambah besarnya juga laba persih yang didapatkan maka ROA pun akan kian bertambah.

H2 : Perputaran Total Aset memberi pengaruh positif signifikan pada Profitabilitas (ROA).

\section{Teori Pengaruh Perputaran Aktiva Tetap Pada Profitabilitas (ROA)}

Sebagaimana yang diungkapkan (Fahmi, Analisis Laporan Keuangan, 2014) bahwa "Ratio fixed assets turn over dinamakan pula perputaran aktiva tetap. Rasio ini guna mengetahui berapa jauh aktiva tetap perusahaan mempunyai tingkat perputaran secara efisien, serta berdampak terhadap keuangan perusahaan."Berdasarkan penelitian (Agleintan, 2019) bahwa bertambah tingginya tingkat perputaran aktiva tetap menentukan perusahaan mempunyai manajemen aktiva yang bagus, yang mana seluruh aktiva yang dipunyai perusahaan dipergunakan secara efisien serta efektif, maka tidak terdapat aktiva yang menumpuk. Lantaran perputaran aktiva yang besar sehingga kas yang masuk juga bertambah akibat dari operasional yang berlangsung secara tinggi dan tepat pula.

H3 : Perputaran Aktiva Tetap memberi pengaruh pada Profitabilitas (ROA).

\section{Teori Pengaruh Leverage (DER) Pada Profitabilitas (ROA)}

Sebagaimana yang diungkapkan (Kasmir, 2016), bahwa: "rasio solvabilitas (Leverage) ialah rasio yang dipergunakan sebagai pengukuran berapa jauh aset perusahaan didanai oleh utang. DER ialah rasio yang dipergunakan dalam mengevaluasi ekuitas serta utang. Rasio ini dipakai guna melihat tiap rupiah yang modal sendiri yang dipergunakan sebagai penjaminan utang.Berdasarkan penelitian (Wartono, 2018) Jika total hutang perusahaan yang naik setiap tahunnya mengakibatkan perusahaan tidak bisa menutupi jumlah aset yang akan dipergunakan dalam perkembangan perusahaan. Karena mempunyai signifikansi diatas 0,05 maka dalam penelitiannya debt to equity memberi pengaruh akan tetapi tidak signifikan pada ROA.

H4 : Debt to Equity memberi pengaruh tetapi tidak signifikan pada ROA.

\section{Kerangka Konseptual}

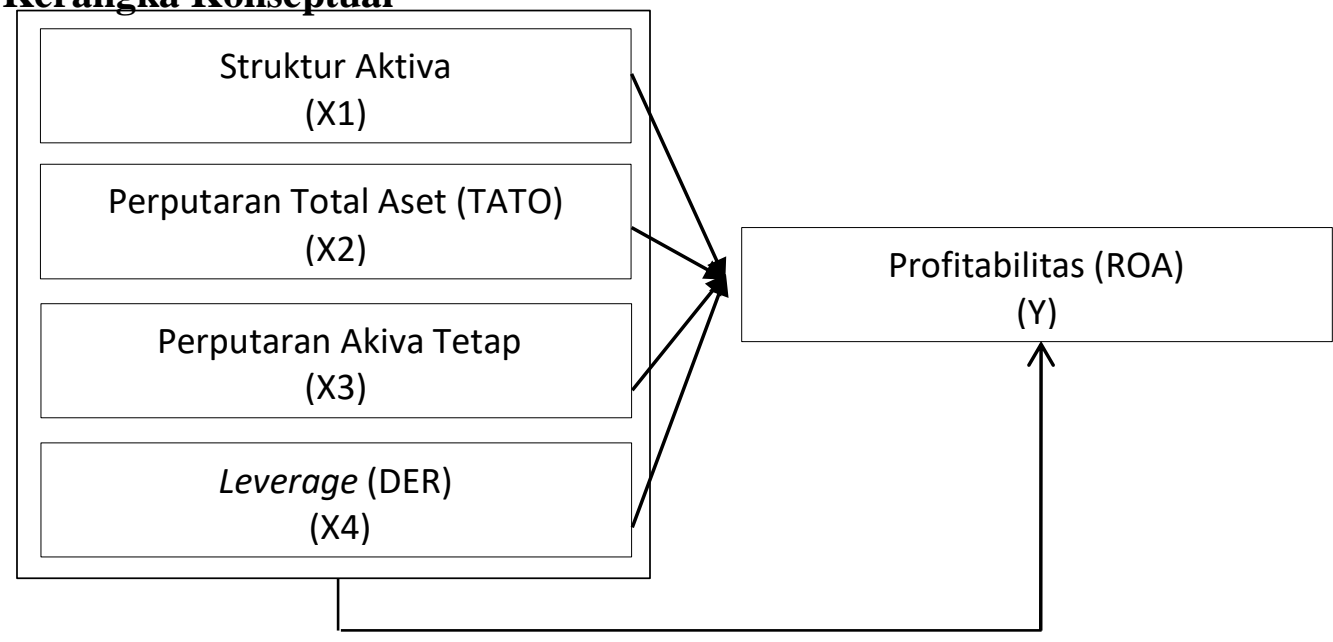




\section{Metode Penelitian}

\section{METODE}

Penelitian ini menerapkan metode penelitian kuantitatif. Sebagaimana yang diungkapkan (Sugiyono, Metode Penelitian Kuantitatif, Kualitatif Dan R\&D, 2013), penelitian kuantitatif bisa didefinisikan sebagai metode yang didasarkan dari filsafat positivisme, dipakai guna meneliti suatu sampel atau populasi tertentu, secara umum teknik pengambilan sampel diambil secara acak, dari pengumpulan data menerapkan instrument penelitain analisis data yang sifatnya statistik/kuantitatif yang mempunyai tujuan sebagai pengujian hipotesis yang sudah ditentukan.

\section{Populasi dan Sampel}

Secara umum populasi yaitu setiap subyek ataupun obyek yang memiliki karakteristik serta kualitas tertentu yang peneliti terapkan untuk dipahami lalu menarik simpulannya. Sampel yaitu sebagai dari karakteristik dan jumlah yang dipunyai ialah wilayah generalisasi yang mencakup obyek/subyek yang berkualitas oleh populasi tersebut (Sugiyono, Metode Penelitian Kuantitatif , 2018).

Sesuai pengertian diatas penarikan sampel didapat dari teknik purposive sampling, dari dasar ketentuan yakni:

Tabel 2. Pemilihan Sampel

\begin{tabular}{|c|l|c|}
\hline No & Keterangan & Jumlah \\
\hline 1 & $\begin{array}{l}\text { Perusahaan Sub Sektor Konstruksi Bangunan yang sudah dan masih } \\
\text { terdaftar di BEI periode 2015-2019 }\end{array}$ & 20 \\
\hline 2 & $\begin{array}{l}\text { Perusahaan Sub Sektor Konstruksi Bangunan yang tidak menerbitkan } \\
\text { dan mempublikasikan laporan keuangannya secara lengkap periode } \\
2015-2019\end{array}$ & (1) \\
\hline 3 & $\begin{array}{l}\text { Perusahaan Sub Sektor Konstruksi Bangunan yang mengalami } \\
\text { kerugian selama periode 2015-2019 }\end{array}$ & $(1)$ \\
\hline & Jumlah Sampel & 18 \\
\hline & Jumlah Periode & 50 \\
\hline
\end{tabular}

\section{Identifikasi dan Definisi Operasional Variabel Penelitian}

\begin{tabular}{|c|l|c|c|}
\hline VARIABEL & \multicolumn{1}{|c|}{ DEFINISI OPERASIONAL } & \multicolumn{1}{|c|}{ INDIKATOR } & SKALA \\
\hline $\begin{array}{c}\text { Struktur Aktiva } \\
\text { (X1) }\end{array}$ & $\begin{array}{l}\text { Struktur Aktiva yaitu susunan aktiva } \\
\text { umumnya industri / manufaktur yang } \\
\text { kebanyakan modal tertanam di aktiva } \\
\text { tetap, memiliki kecenderungan } \\
\text { mempergunakan modal sendiri daripada } \\
\text { modal asing / hutang hanyalah menjadi } \\
\text { pelengkap. }\end{array}$ & Struktur Aktiva & Aktiva Tetap \\
Total Aktiva & Rasio \\
$\begin{array}{c}\text { Perputaran Total } \\
\text { Aset } \\
\text { (X2) }\end{array}$ & $\begin{array}{l}\text { Total Assets Turnover ialah rasio yang } \\
\text { dipakai dalam mengetahui keefektifkan } \\
\text { total aset yang dipunyai perusahaan } \\
\text { untuk menciptakan penjualan ataupun } \\
\text { mempunyai maksud lain guna melihat } \\
\text { sebanyak apa jumlah penjualan yang }\end{array}$ & $\begin{array}{l}\text { Total Asset Turnover } \\
\text { (TATO) }\end{array}$ & Rasio \\
\hline
\end{tabular}




\begin{tabular}{|c|c|c|c|}
\hline & $\begin{array}{l}\text { hendak dicapai melalui masing-masing } \\
\text { modal yang ditanamkan di total asset. }\end{array}$ & & \\
\hline $\begin{array}{l}\text { Perputaran } \\
\text { Aktiva Tetap } \\
\text { (X3) }\end{array}$ & $\begin{array}{l}\text { Sesuai pemaparan Irham Fahmi (2014), } \\
\text { menyebutkan Rasio fixed assets turnover } \\
\text { / Rasio Perputaran Aktiva Tetap } \\
\text { merupakan rasio yang mengamati } \\
\text { seberapa jauh aktiva tetap yang dipunyai } \\
\text { oleh sebuah perusahaan mempunyai } \\
\text { perputaran dengan efektif, serta memberi } \\
\text { pengaruh kepada keuangan perusahaan. }\end{array}$ & $\begin{array}{l}\text { Total Asset Turnover } \\
=\frac{\text { Penjualan }}{\text { Aktiva tetap }}\end{array}$ & Rasio \\
\hline $\begin{array}{l}\text { Leverege (DER) } \\
\quad \text { (X4) }\end{array}$ & $\begin{array}{l}D E R \text { yaitu rasio yang dipergunakan } \\
\text { dalam menilai hutang dengan ekuitas. } \\
\text { Guna mengetahui rasio ini secara } \\
\text { melakukan perbandingan diantara semua } \\
\text { hutang, seperti hutang lancar dan segala } \\
\text { ekuitas }\end{array}$ & $\begin{array}{l}\text { Debt to Equity Ratio } \\
\text { (DER) } \\
=\frac{\text { Total Liabilitas }}{\text { Total Equity }}\end{array}$ & Rasio \\
\hline $\begin{array}{l}\text { Rasio } \\
\text { Profitabilitas } \\
\text { (ROA) } \\
\text { (Y) }\end{array}$ & $\begin{array}{l}\text { Rasio Profitabilitas yaitu rasio yang } \\
\text { dipakai guna melihat potensi perusahaan } \\
\text { untuk mendatangkan keuntungan melalui } \\
\text { kegiatan normal usahanya. }\end{array}$ & $\begin{array}{l}\text { Return On Assets } \\
=\frac{\text { Laba Bersih }}{\text { Total Aset }}\end{array}$ & Rasio \\
\hline
\end{tabular}

\section{Statistik Deskriptif}

\section{HASIL}

Analisis statistik deskriptif mendeskripsikan sebuah data yang dapat diukur mempergunakan nilai mean, maksimum minimum, serta standar deviasi yang terdapat dalam penelitian. Hasil penelitian statistik deskriptif bisa diamati di tabel 3 .

Tabel 3. Hasil Uji Statistik Deskriptif

\begin{tabular}{|l|c|c|c|c|c|}
\hline & N & Minimum & Maximum & Mean & $\begin{array}{c}\text { Std. } \\
\text { Deviation }\end{array}$ \\
\hline Struktur Aktiva & 90 &, 0059 &, 7488 &, 162782 &, 1712316 \\
\hline $\begin{array}{l}\text { Perputaran Total } \\
\text { Aset }\end{array}$ & 90 &, 0774 & 2,0025 &, 715199 &, 3615642 \\
\hline $\begin{array}{l}\text { Perputaran Aktiva } \\
\text { Tetap }\end{array}$ & 90 &, 4557 & 100,9790 & 11,977908 & 17,9053751 \\
\hline Leverage (DER) & 90 &, 2235 & 35,4656 & 2,081559 & 3,7285133 \\
\hline Profitabilitas (ROA) & 90 &, 2488 &, 2422 &, 040986 &, 0597156 \\
\hline Valid N (listwise) & 90 & & & & \\
\hline
\end{tabular}

Sumber : Data Output SPSS

Berdasarkan hasil statistik deskriptif di tabel tersebut, bisa dijelaskaan bahwa :

1. Variabel Struktur Aktiva (X1) mempunyai sampel sejumlah 90, dengan skor terendah 0,0059, skor tertinggi 0,7488 sementara skor mean 0,162782 dan standar deviasi senilai 0,1712316 .

2. Variabel Leverage (DER) memiliki sampel sejumlah 90, dengan skor terendah 0,2235 , skor tertinggi 35,4656, sementara mean senilai 2,081559 dengan standar deviasi senilai 3,7285133.

3. Variabel Perputaran Total Aset (X2) mempunyai sampel sejumlah 90, dengan skor 
terendah 0,0774 , skor tertinggi 2,0025 sementara skor mean 0,715199 dan nilai standar deviasi 0,3615642.

4. Variabel Perputaran Aktiva Tetap (X3) mempunyai sampel sejumlah 90, dengan skor terendah 0,4557 , skor tertinggi 100,9790 sementara skor mean 11,977908 dan nilai standar deviasi 17,9053751 .

5. Variabel Profitabilitas (ROA) mempunyai sampel sejumlah 90, dengan skor terendah - 0,2488, skor tertinggi 0,2422, sementara skor mean 0,040986 dan standar deviasi senilai 0,0597156 .

Uji Normalitas fungsinya agar dapat melihat alokasinya normal / tidak melalui model regresi variabel terikat/bebas. Uji normalitas secara menganalisis grafik yakni menggunakan grafik Histogram serta Normal P-P Plot of Regression Standarizied Residual. Kemudian uji normalitas juga bisa dilaksanakan mempergunakan uji Kolmogorov- Smirnov.

\section{Gambar 2. Hasil Uji Normalitas Grafik Histogram}

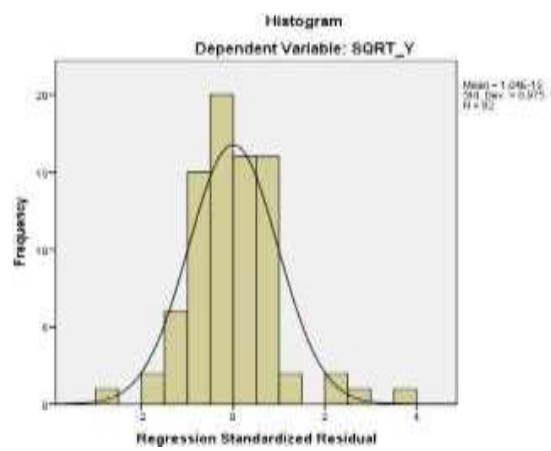

Sumber : Data Output SPSS

Dari gambar 2, bisa diketahui grafik histogram memperlihatkan pola distribusi normal.

\section{Gambar 3. Hasil Uji Normalitas Grafik Normal P-P Plot}

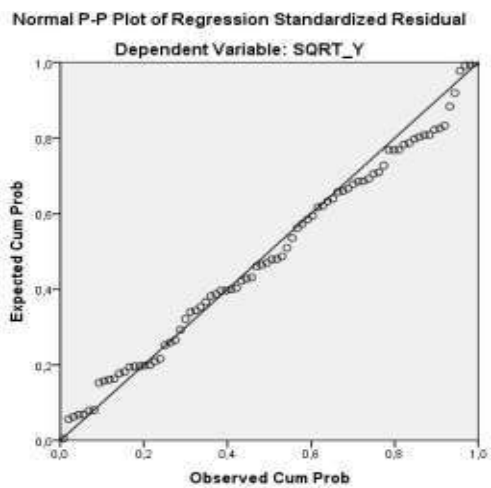

Sumber : Data Output SPSS

Dari gambar 3, bisa diketahui grafik normal p-plot membuktikan gambaran pola data yang baik, dimana penyebaran data disekitar garis diagonal yang berarti asumsi normalitas sudah dipenuhi. 
Tabel 4. Hasil Uji Normalitas One-Sample Kolmogrov-Smirnov Test

\begin{tabular}{|l|r|r|}
\hline \multicolumn{2}{|l|}{} & Unstandardized Residual \\
\hline $\mathrm{N}$ & 82 \\
\hline \multirow{2}{*}{$\begin{array}{l}\text { Normal } \\
\text { Parameters }\end{array}$} & a,b & OE-7 \\
\hline & Std. Deviation &, 06376531 \\
& Absolute &, 088 \\
\cline { 2 - 3 } & Positive &, 088 \\
\cline { 2 - 3 } & Negative &,- 061 \\
\hline \multicolumn{2}{|l|}{ Kolmogrove-Smirnov Z } &, 795 \\
\hline Asymp. Sig. (2-tailed) &, 552 \\
\hline \multicolumn{2}{|l|}{ a. Test distribution is Normal. } \\
\hline \multicolumn{2}{|l|}{ b. Calculated from data. } \\
\hline
\end{tabular}

Sumber : Data Output SPSS

Hasil dari kolmogrov-smirnov pada tabel 4, membuktikan nilai signifikan atau Asymp. Sig (2-failed) sebesar 0,552, hasilnya lebih besar dari 0,05, artinya data memberi distribusi normal.

\section{Uji Multikolinearitas}

Model regresi yang baik harusnya tidak ada hubungan antar variabel independen. Uji ini bisa diketahui dari VIF (Variabel Inflation Factor) antar variabel bebas. Jika skor tolerance $>0.1$ atau skor $\mathrm{VIF}<10$ sehingga tidak ada multikoliniearitas.

Tabel 5. Hasil Uji Multikolinearitas

\begin{tabular}{|c|c|c|c|c|c|c|c|c|}
\hline \multicolumn{9}{|c|}{ Coefficients $^{\mathrm{a}}$} \\
\hline \multirow{2}{*}{\multicolumn{2}{|c|}{ Model }} & \multicolumn{2}{|c|}{$\begin{array}{c}\text { Unstandardized } \\
\text { Coefficients }\end{array}$} & \multirow{2}{*}{$\begin{array}{c}\text { Standardized } \\
\text { Coefficients } \\
\text { Beta }\end{array}$} & \multirow[t]{2}{*}{$\mathrm{t}$} & \multirow[t]{2}{*}{ Sig. } & \multicolumn{2}{|c|}{$\begin{array}{c}\text { Collinearity } \\
\text { Statisties }\end{array}$} \\
\hline & & $\mathrm{B}$ & $\begin{array}{l}\text { Std. } \\
\text { Error }\end{array}$ & & & & Tolerance & VIF \\
\hline \multirow{5}{*}{1} & (Constant) &,- 083 & 059 & & $-1,403$ &, 165 & & \\
\hline & SQRT_X1 & ,202 & ,062 & ,428 & 3,269 & ,002 & ,417 & 2,398 \\
\hline & SQRT_X2 & ,207 &, 048 & ,474 & 4,349 &, 000 & 602 & 1,662 \\
\hline & SQRT_X3 & ,019 & ,006 & ,417 & 2,861 & ,005 & ,336 & 2,973 \\
\hline & SQRT_X4 &,- 004 & , 020 &,- 021 &,- 218 & ,828 & ,802 & 1,246 \\
\hline
\end{tabular}

Sumber : Data Output SPSS

Berdasarkan tabel tersebut bisa diketahui bahwa hasil dari uji multikolinearitas yaitu:

1. Variabel Perputaran Aktiva Tetap (X3) mempunyai skor tolerance senilai 0,336> 0,1 dan skor VIF senilai $2,973<10$.

2. Variabel Struktur Aktiva (X1) memiliki skor tolerance senilai 0,417>0,1 atau skor VIF senilai 2,398< 10.

3. Variabel Perputaran Total Aset (X2) memiliki skor tolerance senilai 0,602 >0,1 atau skor VIF senilai $1,662<10$.

4. Variabel Leverage (DER) mempunyai skor tolerance senilai 0,802 >0.1 atau skor VIF sebesar 1,246 < 10. Bisa disimpulkan jika tidak ada variabel bebas dengan skor tolerance 
$<0,1$ serta tidak terdapat skor VIF $>10$. Sehingga bisa disimpulkan jika tidak ditemukan masalah multikolinearitas antar variabel bebas.

\section{Uji Autokorelasi}

Uji ini tujuannya agar dapat memeriksa apakah pada model regresi ditemukan hubungan antara kekeliruan penggangu di periode $t$ dan kekeliruan di periode $t-1$. Model regresi bisa dianggap baik bila tidak terdapat autokorelasi. Untuk menguji autokorelasi bisa mempergunakan uji Durbin Watson.

Tabel 6. Hasil Uji Autokorelasi

\begin{tabular}{|c|c|c|c|c|c|}
\hline \multicolumn{6}{|c|}{ Model Summary $^{b}$} \\
\hline $\begin{array}{l}\text { Mode } \\
1\end{array}$ & $\mathrm{R}$ & R Square & $\begin{array}{c}\text { Adjusted R } \\
\text { Square }\end{array}$ & $\begin{array}{l}\text { Std. Error } \\
\text { the Estimate }\end{array}$ & $\begin{array}{l}\text { Durbin- } \\
\text { Waston }\end{array}$ \\
\hline 1 &, $671^{\mathrm{a}}$ & ,450 &, 422 &, 06540 & 1,754 \\
\hline
\end{tabular}

Sumber : Data Output SPSS

Dari tabel 6 di atas, hasil uji autokorelasi membuktikan variabel penelitian dengan skor Durbin-Watson (d) senilai 1,754 yang teletak pada du $<\mathrm{d}<4$ - du $(1,5406<1,754<$ 2,2554), maka kesimpulannya tidak ada autokorelasi negatif ataupun positif

\section{Uji Heteroskedastisitas}

Uji ini tujuannya agar dapat memeriksa apakah pada model regresi terjadi ketidaksamaan varian. Uji heteroskedasitas bisa diamati dari uji grafik scatterplot.

\section{Gambar 4. Hasil Uji Heteroskedastisitas}

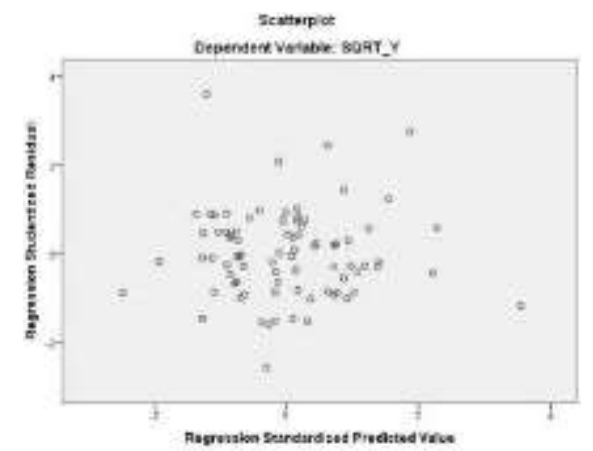

Dari gambar tersebut bisa diketahui titik-titik penyebaran nya secara random baik di atas maupun di bawah angka $\mathrm{O}$ dalam sumbu $\mathrm{Y}$. Sehingga kesimpulannya tidak ditemukan heteroskedastisitas.

\section{Analisis Data Penelitian}

\section{Analisis Regresi Linear Berganda}

Dalam penelitian ini, hasil analisis linear berganda yaitu: 
Tabel 7. Hasil Uji Analisis Linear Berganda

\begin{tabular}{|c|c|c|c|c|c|c|}
\hline \multicolumn{7}{|c|}{ Coefficients $^{\mathrm{a}}$} \\
\hline \multirow{2}{*}{\multicolumn{2}{|c|}{ Model }} & \multicolumn{2}{|c|}{$\begin{array}{c}\text { Unstandardized } \\
\text { Coefficients }\end{array}$} & Standardized & \multirow[t]{2}{*}{$\mathrm{t}$} & \multirow[t]{2}{*}{ Sig. } \\
\hline & & $\mathrm{B}$ & $\begin{array}{l}\text { Std. } \\
\text { Error }\end{array}$ & Beta & & \\
\hline \multirow{5}{*}{1} & (Constant) &,- 083 & 059 & & $-1,403$ & , 165 \\
\hline & SQRT_X1 & 202 & ,062 & ,428 & 3,269 & ,002 \\
\hline & SQRT_X2 & 207 &, 048 & ,474 & 4,349 &, 000 \\
\hline & SQRT_X3 & ,019 & ,006 & ,417 & 2,861 & ,005 \\
\hline & SQRT_X4 &,- 004 &, 020 &,- 021 &,- 218 & ,828 \\
\hline \multicolumn{7}{|c|}{ a. Dependent Variabel: SQRT_Y } \\
\hline
\end{tabular}

Sumber : Data Output SPSS

Berdasarkan hasil tabel tersebut, membuktikan persamaan regresi linear berganda pada penelitian ini yaitu:

SQRT_Profitabilitas $($ ROA $)=-0,083+0,202 S Q R T \_S t r u k t u r$ Aktiva +

0,207SQRT_Perputaran Total Aset + 0,019SQRT_Perputaran Aktiva Tetap + 0,004SQRT_Leverage (DER) + e

Hasil penjelasan dari regresi tersebut, yaitu:

1. Skor a senilai $-0,083$ berarti bila variabel Struktur Aktiva (X1), Perputaran Total Aset (X2), Perputaran Aktiva Tetap (X3) dan Leverage (DER) dianggap konstan, maka Profitabilitas (ROA) dalam perusahaan Sub Sektor Konstruksi Bangunan yang tercatat pada BEI tahun 2015-2019 yaitu senilai -0,083.

2. Angka koefisien Perputaran aktiva tetap (X3) adalah senilai 0,019. Artinya bahwa tiap terjadi perubahan Perputaran Aktiva Tetap (X3) satu kali maka ROA (Profitabilitas) juga akan terjadi penambahan senilai 0,019.

3. Angka koefisien Struktur Aktiva (X1) senilai 0,202. Artinya setiap terjadi perubahan Struktur Aktiva (X1) satu kali maka Profitabilitas (ROA) juga akan terjadi kenaikan senilai 0,202 .

4. Angka koefisien Perputaran Total Aset (X2) yaitu senilai 0,207. Artinya setiap terjadi perubahan Perputaran Total Aset (X2) satu kali maka Profitabilitas (ROA) juga akan terjadi kenaikan senilai 0,207.

5. Angka koefisien Leverage (DER) adalah -0,004. Artinya setiap terjadi perubahan DER satu kali maka ROA (Profitabilitas) juga akan terjadi kenaikan senilai 0,004.

Koefisien Determinasi $\left(\mathbf{R}^{2}\right)$

Koefisien Determinasi (R Square) yang simbolnya yaitu " $\mathrm{R}$ ", artinya sebagai distribusi pengaruh dari variabel bebas (X) pada variabel dependen ( $\mathrm{Y}$ ), ataupun memperkirakan serta melihat sebesar apa sumbangan pengaruh dari variabel $\mathrm{X}$ secara bersamaan pada variabel $\mathrm{Y}$. 
Tabel 8. Hasil Uji Koefisien Determinasi $\left(\mathbf{R}^{2}\right)$

\begin{tabular}{|l|c|c|c|c|c|}
\hline \multicolumn{5}{|c|}{ Model Summary $^{\mathbf{b}}$} \\
\hline $\begin{array}{l}\text { Mode } \\
1\end{array}$ & $\mathrm{R}$ & R Square & $\begin{array}{c}\text { Adjusted R } \\
\text { Square }\end{array}$ & $\begin{array}{c}\text { Std. Error } \\
\text { the Estimate }\end{array}$ & $\begin{array}{c}\text { Durbin- } \\
\text { Waston }\end{array}$ \\
\hline 1 &, $671^{\mathrm{a}}$ &, 450 &, 422 &, 06540 & 1,754 \\
\hline \multicolumn{2}{|l|}{ a. Predictors: (Constant), SQRT_X4, SQRT_X3,SQRT_X2, SQRT_X1 } \\
\hline \multicolumn{2}{l}{ b. Dependent Variable: SQRT_Y } \\
\hline
\end{tabular}

Sumber : Data Output SPSS

Berdasar tabel diatas, nilai kofisien determinasi (R Square) senilai 0,450. Skor R Square 0,450 berasal dari hasil kuadrat skor kofisien korelasi ( $\mathrm{R}$ yakni 0,671 X 0,671= 0,450 ), besarnya nilai $\mathrm{R}$ Square yaitu 0,450 sama dengan (45\%). Angka ini mengandung arti bahwa variabel $\mathrm{X}$ secara simultan berpengaruh pada variabel $\mathrm{Y}$ sebesar $45 \%$, sementara sisanya $(100 \%-45 \%=55 \%)$ di pengaruhi oleh variabel lainnya yang tidak di bahas dalam penelitian ini.

\section{Pengujian Hipotesis Secara Simultan (F)}

Pada penelitian diketahui dari banyaknya sampel (n) ialah 82 serta jumlah variabel keseluruhan $(\mathrm{k})$ yaitu 5 maka didapat df1 = k-1 $(5-1=4)$ atau df2 $=(\mathrm{n}-\mathrm{k})(82-$ $5=77)$. Berdasarkan hasil penelitian ini diperoleh skor $F$ ataupun signifikan secara bersamaan yaitu:

Tabel 9. Hasil Pengujian Hipotesis Secara Simultan (F)

\begin{tabular}{|c|c|c|c|c|c|c|}
\hline \multicolumn{7}{|c|}{ ANOVA $^{\mathrm{a}}$} \\
\hline \multicolumn{2}{|c|}{ Model } & Sum of & df & Mean & $\mathrm{F}$ & Sig. \\
\hline & Regression & 270 & 4 & ,067 & 15,765 & $.000^{\mathrm{b}}$ \\
\hline & Residual & ,329 & 77 & ,004 & & \\
\hline & Total &, 599 & 81 & & & \\
\hline & and & SQRT_Y & & & & \\
\hline
\end{tabular}

\section{Sumber : Data Output SPSS}

Berdasarkan tabel 9 tersebut, dilihat skor signifikan untuk pengaruh Struktur Aktiva, Perputaran Total Aset, Perputaran Aktiva Tetap, dan secara bersamaan Leverage (DER) terhadap Profitabilitas (ROA) yaitu senilai 0,000 < 0,05 atau skor $F_{\text {hitung }} 15,765>$ 2,33 maka dapat disimpulkan Perputaran Aktiva Tetap, Struktur Aktiva, Perputaran Total Aset, dan Leverage (DER) secara simultan berpengaruh terhadap Profitabilitas (ROA).

\section{Pengujian Hipotesis Secara Parsial (t)}

Ketentuan signifikan ataupun tidak hipotesis secara parsial yakni:

1. Bila variabel bebas $<0,05$ maka variabel nya signifikan

2. Bila variabel bebas $>0,05$ maka variabel nya tidak signifikan 
Tabel 10. Hasil Pengujian Hipotesis Secara Parsial (t)

\begin{tabular}{|c|c|c|c|c|c|c|}
\hline \multicolumn{7}{|c|}{ Coefficients $^{\mathbf{a}}$} \\
\hline \multirow{2}{*}{\multicolumn{2}{|c|}{ Model }} & \multicolumn{2}{|c|}{$\begin{array}{l}\text { Unstandardized } \\
\text { Coefficients }\end{array}$} & \multirow{2}{*}{$\begin{array}{c}\text { Standardized } \\
\text { Coefficients } \\
\text { Beta }\end{array}$} & \multirow[t]{2}{*}{$\mathrm{t}$} & \multirow[t]{2}{*}{ Sig. } \\
\hline & & $\mathrm{B}$ & $\begin{array}{c}\text { Std. } \\
\text { Error }\end{array}$ & & & \\
\hline \multirow{5}{*}{1} & (Constant) &,- 083 & ,059 & & $-1,403$ & , 165 \\
\hline & SQRT_X1 & ,202 & ,062 & ,428 & 3,269 & 002 \\
\hline & SQRT_X2 & ,207 &, 048 & ,474 & 4,349 & 000 \\
\hline & SQRT_X3 & ,019 & ,006 & ,417 & 2,861 & 005 \\
\hline & SQRT_X4 &,- 004 &, 020 &,- 021 &,- 218 & ,828 \\
\hline
\end{tabular}

Berdasar tabel diatas bisa diambil kesimpulan yaitu:

1. Variabel Struktur Aktiva (X1) memiliki hasil $t_{\text {hitung }}>t_{\text {tabel }}$ sebesar 3,269 $>1,991$ serta angka signifikansi $0,002<0,05$, menolak $\mathrm{H}_{0}$ dan menerima $\mathrm{H}_{\mathrm{a}}$, artinya Struktur Aktiva secara parsial memberi pengaruh signifikan terhadap Profitabilitas (ROA) di perusahaan sub Sektor Konstruksi Bangunan yang Tercatat dalam BEI periode 20152019. Hasilnya selaras dengan (Rahmi, 2019). Kian besar aktiva tetap yang perusahaan miliki, maka aktivitas pendanaan pun kian tinggi. Bisa dipastikan bahwa jumlah aset tetap perusahaan banyak jika struktur aktiva perusahaan besar.

2. Variabel Perputaran Total Aset (X2) memiliki $t_{\text {hitung }}>t_{\text {tabel }}$ sebesar 4,349>1,991 dan skor signifikan $0,000<0,05$, menolak $\mathrm{H}_{0}$ dan menerima Ha, artinya Perputaran Total Aset secara parsial memberi pengaruh signifikan terhadap Profitabilitas (ROA) di perusahaan sub Sektor Konstruksi Bangunan yang Tercatat dalam BEI Tahun 20152019. Hasil penelitian selaras dengan (Budiang, 2017) yang menyatakan kian tinggi rasio membuktikan keberhasilan perusahaan mempergunakan aktiva ataupun kekayaannya pada penjualan. Kian besar penjualan serta pengeluaran yang semakin kecil maka laba bersih yang didapat juga kian besar, maka ROA juga akan naik.

3. Variabel Perputaran Aktiva Tetap (X3) memilki $t_{\text {hitung }}>t_{\text {tabel }}$ sebesar 2,861 $>1,991$ pada angka signifikansi $0,005<0,05$ artinya menolak $\mathrm{H}_{0}$ dan menerima $\mathrm{H}_{\mathrm{a}}$, maka Perputaran Aktiva Tetap secara parsial memberi pengaruh signifikan terhadap Profitabilitas (ROA) di perusahaan sub Sektor Konstruksi Bangunan yang Tercatat dalam BEI Tahun 2015- 2019. Hasilnya sejalan dengan (Agleintan, 2019) yang memaparkan bahwa tingkat perputaran aktiva tetap yang kian tinggi, perusahaan mempunyai pengelolaan kekayaan yang baik, dimana seluruh kekayaan yang perusahaan miliki dipergunakan secara efisien ataupun efektif, dengan demikian tidak ada aset yang menumpuk ataupun tidak dipergunakan.

4. Variabel Leverage (DER) (X4) memilki $t_{\text {hitung }}<\mathrm{t}_{\text {tabel }}$ sebesar $-0,218<1,991$ pada angka signifikansi $0,828>0,05$ artinya menolak $\mathrm{H}_{0}$ dan menerima $\mathrm{H}_{\mathrm{a}}$ artinya Leverage (DER) secara parsial memberi pengaruh negatif dan juga tidak signifikan terhadap ROA dalam perusahaan sub Sektor Konstruksi Bangunan yang Tercatat pada BEI Periode 2015-2019. Hasil penelitian ini selaras dengan (Wartono, 2018) jika pinjaman perusahaan naik tiap tahunnya, maka perusahaan tidak bisa memenuhi jumlah aktiva perusahaan yang hendak dipergunakan pada keberlanjutan perusahaan. Dalam penelitiannya debt to equity berpengaruh namun tidak signifikan pada Return on asset sebab taraf signifikasi variable debt to equity di atas 0.05 . 


\section{KESIMPULAN}

Dari hasil analisis uji hipotesis yang mempergunakan program SPSS, didapat kesimpulan yaitu, Struktur Aktiva, Perputaran Total Aset, Perputaran Aktiva Tetap memberi pengaruh signifikan secara parsial terhadap ROA (Profitabilitas) dalam perusahaan sub Sektor Konstruksi Bangunan yang Teregistrasi pada BEI Tahun 20152019. Sedangkan Leverage (DER) (X4) memberi pengaruh negatif dan juga tidak signifikan secara parsial pada ROA (Profitabilitas) di perusahaan sub Sektor Konstruksi Bangunan yang Tercatat dalam BEI Tahun 2015-2019. Dengan cara simultan Struktur Aktiva, Perputaran Aktiva Tetap, Perputaran Total Aset, serta Leverage (DER) berpengaruh signifikan terhadap Profitabilitas (ROA) di perusahaan sub Sektor Konstruksi Bangunan yang Terdaftar di BEI Tahun 2015-2019.

\section{REFERENSI}

Agleintan, E. D. (2019). Pengaruh Perputaran Piutang Dan Perputaran Aktiva Tetap Terhadap Profitabilitas (Pada Perusahaan Perdagangan Eceran yang Terdaftar di Bursa Efek Indonesia Pada Tahun 2013. PRIMANOMICS : Jurnal Ekonomi Dan Bisnis - Vol. 17, No. 3.

BEI. (2019). Laporan Keuangan Dan Tahunan Tahun 2015-2019. Diambil kembali dari idx: https://www.idx.co.id/perusahaan-tercatat/laporan-keuangan-dan-tahunan/

Budiang, F. D. (2017). Pengaruh Perputaran Total Aset, Perputaran Piutang Dan Perputaran Persediaan Terhadap ROA Pada Perusahaan Sub Sektor Perdagangan Eceran Yang Terdaftar Di BEI. Jurnal EMBA. Vol.5 No.2.

Fahmi, I. (2014). Analisis Laporan Keuangan. Alfabeta.

Fahmi, I. (2014). Analisis Laporan Keuangan. Bandung: Alfabeta.

Fahmi, I. (2014). Pengantar Manajemen Keuangan. Bandung: Alfabeta.

Ghozali, I. (2016). Aplikasi Analisis Multivariete Dengan Program IMB SPSS 23 (Edisi

8) Cetakan ke VIII. Semarang: Universitas Diponegoro.

Hery. (2015). Analisis Laporan Keuangan. Edisi 1. Yogyakarta: CAPS.

Indriyani, I. D. (2017). Analisis Pengaruh Current Ratio Dan Total Asset Turnover Terhadap Return On Asset (Studi Kasus Pada PT Pelabuhan Indonesia II (Persero) Cabang Pangkalbalam). Jurnal Ilmiah Akuntansi Bisnis \& Keuangan (JIABK). Vol. 10, No. 2. ISSN : 2355-9047.

Kasmir. (2016). Analisis Laporan Keuangan. Jakarta: PT Raja Grafindo Persada.

Nuriyanto. (2019). Analisis Pengaruh Tingkat Pertumbuhan Asset (Asset Growth) Dan

Struktur Aktiva Terhadap Profitabilitas (ROA) Dengan Capital Structure Sebagai Variabel Intervening Pada Bank Umum Syariah Di Indonesia Periode 2016-2018. E-Repository IAIN Salatiga.

Rahmi, H. (2019). Pengaruh Struktur Aktiva Dan Struktur Modal Terhadap Profitabilitas Pada PT Kimia Farma Tbk. Jom Fisip, Vol. 6 : Edisi II.

Riyanto, B. (2013). Dasar-Dasar Pembelanjaan Perusahaan. Edisi Keempat. Yogyakarta: BPFE-Yogyakarta.

Sugiyono. (2013). Metode Penelitian Kuantitatif, Kualitatif Dan R\&D. Bandung : Alfabeta.

Sugiyono. (2018). Metode Penelitian Kuantitatif . Bandung: Alfabeta.

Wartono, T. (2018). Pengaruh Current Ratio (CR) Dan Debt To Equity Ratio Terhadap Return on Asset (Studi Pada PT AstraInternasional, Tbk). Jurnal Kreatif: Pemasaran, Sumber Daya Manusia Dan Keuangan, Volume 6 Nomor 2. 